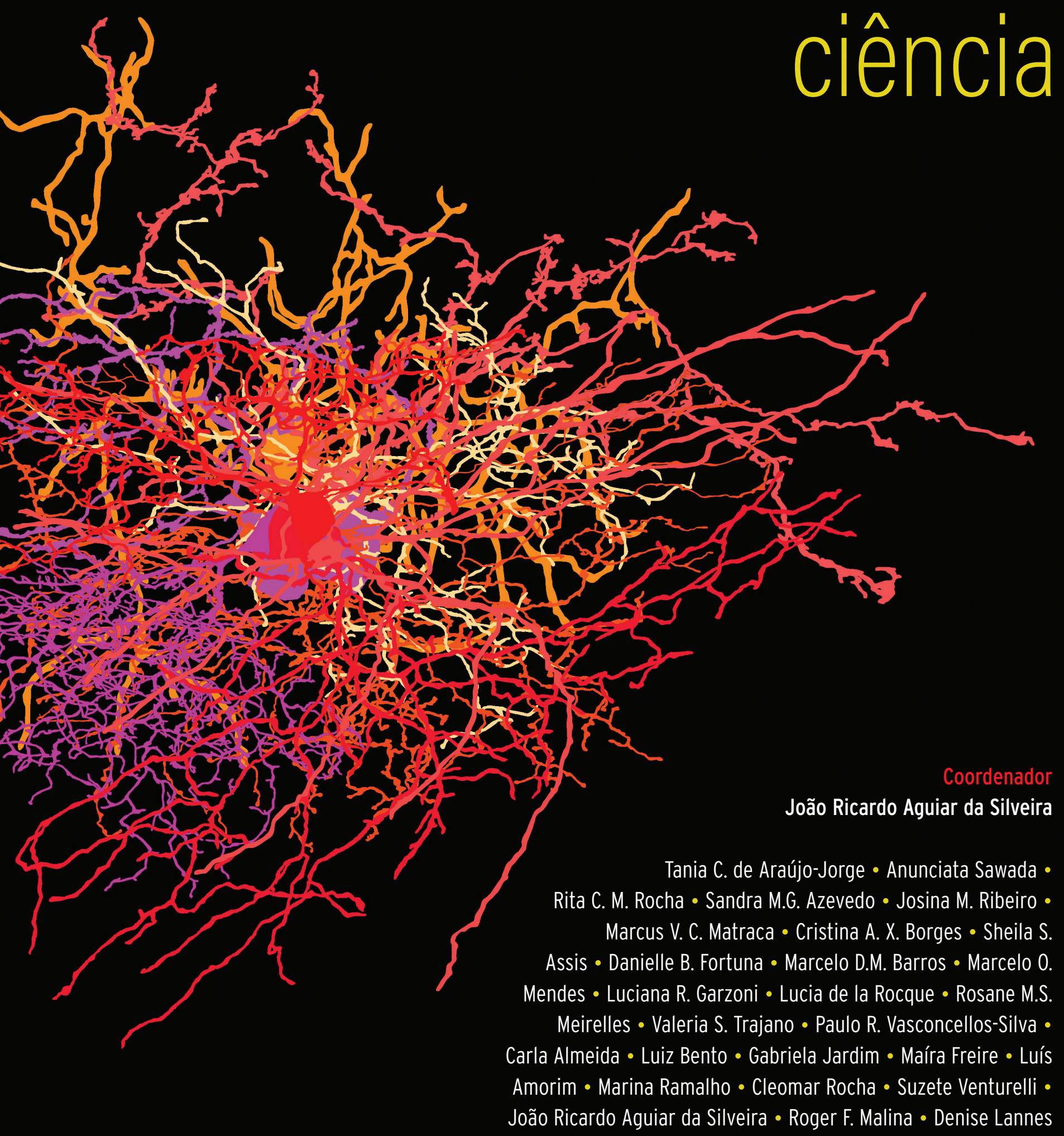




\title{
APRESENTAçÃo
}

\section{ARTE E CIÊNCIA: UMA RECONEXÃO ENTRE AS ÁREAS}

\author{
João Ricardo Aguiar da Silveira
}

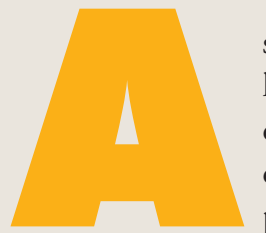

separação entre arte e ciência é um fenômeno relativamente recente em termos históricos. Desde o nascimento da filosofia na Grécia, por volta do século VI a.C., quando o mundo ocidental passou a distinguir a razão do misticismo, até o século XIX, com o advento do positivismo, os conhecimentos científicos e artísticos estiveram intrinsicamente ligados. $\mathrm{O}$ breve período de afastamento, de cerca de 200 anos, parece estar chegando ao fim. Ciência, arte, tecnologia e filosofia, ou seja, raciocínio lógico, criatividade, desenvolvimento de técnicas e capacidade de reflexão e abstração fazem mais sentido conectados e são cada vez mais necessários diante de um mundo cada vez mais complexo.

Instituiçôes de pesquisa e agências de fomento, entre as mais prestigiadas do mundo, têm investido nesse campo. Entre os anos 1996 e 2006, a Welcome Trust investiu cerca de 3 milhōes de libras em 118 projetos. Os objetivos eram estimular o interesse em ciências biomédicas, promover a colaboração criativa e a interdisciplinaridade entre artes e ciências e criar uma massa crítica de artistas interessados em ciências biomédicas [1]. Desde então, a agência do Reino Unido continua fomentando esse campo e tem diversificado muito os objetivos. Da mesma forma, a National Academy of Sciences, Engineering, and Medicine dos Estados Unidos fomenta projetos de integração dessas áreas com verbas específicas [2] e programas permanentes [3]. Universidades como Harvard, Instituto de Tecnologia de Massachusetts (MIT), Stanford, Universidade da Califórnia em Los Angeles (UCLA), Oxford, Sorbonne, Universidade da Austrália Ocidental são apenas alguns exemplos de instituições que têm projetos integrando arte e ciência. Além disso, uma série de centros de pesquisa no mundo tem promovido residências arte-científicas, isto é, colocado juntos artistas e cientistas para pensar de maneira criativa sobre diferentes questôes - como a pesquisa espacial, nas residências na NASA e em outros centros [4], ou a estrutura do universo, na residência da Organização Europeia para a Pesquisa Nuclear (CERN) [5], e a biologia sintética, como no caso do Instituto Max Planck [6], na Alemanha.

Os resultados dessas interaçôes são diversos: a criação de obras artísticas inspiradas pela ciência que chegam a museus ícones da arte contemporânea, como o MoMa em Nova York [7], projetos de extensão de engajamento público [8] e projetos inovadores nas mais diferentes áreas. Neste caso existem trabalhos que vão desde a visualização de dados até a criação de inteligência artificial. Da neurociência à robótica. Da engenharia de tecidos à ética em pesquisas por uma visão não antropocên trica. Da criação de novas metodologias até o questionamento das abordagens reducionistas do método científico. Dada a amplitude da arte e da ciência, as possíveis interaçôes entre essas áreas são ilimitadas.

Além do aprofundamento da relação entre arte e ciência em projetos de pesquisa em centros de referência e nas mais diferentes áreas acadêmicas, a relação entre esses campos tem sido discutida e cada vez mais aplicada na educação. O movimento STEM (acrônimo em inglês para science, technology, engineering and mathematic) surgiu nos Estados Unidos na década de 1990 para identificar qualquer ação ou prática educacional envolvendo as disciplinas de ciência, tecnologia, engenharia e/ou matemática. Depois de alguns anos, pesquisadores passam a advogar que a arte deveria ser integrada às demais áreas, dando origem ao movimento STEM to STEAM. O principal argumento da educação STEAM é promover uma educa- 
ção sem barreiras entre as disciplinas, que promova a criatividade e a inovação. A rede de educadores que abordam essa prática tem gradativamente se espalhado pelo mundo [9].

No Brasil, temos um cenário ambíguo na interação entre arte e ciência. Por um lado, ainda há um grande desconhecimento do campo, inclusive no meio acadêmico. Não há praticamente nenhum investimento por parte das agências de fomento e a maior parte das instituições se limita a promover ou incentivar alguns projetos extensionistas dispersos. Por outro lado, temos pesquisadores que foram trilhando seus próprios caminhos e criando espaços e, com resiliência, têm participado da ampliação desse campo no país. Neste Núcleo Temático são apresentados exemplos de trabalhos feitos no Brasil. A pesquisadora Tania Araújo-Jorge e colaboradores tratam em seu artigo sobre os mais de 30 anos de atividades integrando ciência e arte na Fiocruz. O grupo defende essa abordagem no ensino, em todos os níveis, para a formação de cientistas e para a formação de cidadãos. No artigo seguinte, Carla Almeida e colaboradores abordam ações de ciência e teatro no campo da divulgação científica, dando destaque para as iniciativas do Museu Ciência e Vida/Fundação Cecierj e do Museu da Vida/Fiocruz, ambos no Rio de Janeiro. A partir de uma visão das artes, os pesquisadores Cleomar Rocha e Suzette Venturelli abordam em seu artigo como a arte, a tecnologia e o design podem revolucionar o conceito de cidades inteligentes, envolvendo interatividade, energia, ecologia, mobilidade, arquitetura responsável, sociabilidade e cidadania. Por fim, com a colaboração de Roger Malina e Denise Lannes, faço um retrato do universo acadêmico brasileiro que atua nessa área. Resultado de mais de dois anos de pesquisa, o artigo traz uma análise do perfil de pesquisadores que atuam na relação entre arte e ciência no país quanto à sua formação acadêmica, área de atuação, projetos e produções.

João Ricardo Aguiar da Silveira, coordenador deste Núcleo Temático, é mestre e doutor em educação, gestão e difusão em biociências e pesquisador visitante na Universidade de Harvard e na Universidade do Texas em Dallas. E-mail: silveiraufrj@gmail.com

\section{NOTAS E REFERÊNCIAS}

1. Glinkowski, P.; Bamford, A. Insight and exchange: an evaluation of the Wellcome Trust's Sciart programme. London: Wellcome Trust, 2009.

2. https://www.neh.gov/news/press-release/2016-07-25-0

3. http://www.cpnas.org/events/march2016_daser.pdf

4. http://air.seti.org/about-2/about/

5. http://arts.cern

6. https://www.mpikg.mpg.de/5748813/artist-in-residence-programm-2017

7. https://www.moma.org/collection/works/110251

8. https://www.leonardo.info/laser-talks

9. http://map.stemtosteam.org

\section{GIENGIARTE๑ NO INSTITUTO OSWALDO GRUZ: 30 ANOS DE EXPERIENGIAS NA CONSTRUĢÃO DE UM CONGEITO INTERDISGIPLINAR}

Tania C. de Araújo-Jorge, Anunciata Sawada,

Rita C. M. Rocha, Sandra M.G. Azevedo, Josina M. Ribeiro, Marcus V. C. Matraca, Cristina A. X. Borges, Sheila S. Assis, Danielle B. Fortuna, Marcelo D.M. Barros, Marcelo 0. Mendes, Luciana R. Garzoni, Lucia de la Rocque, Rosane M.S. Meirelles, Valeria S. Trajano, Paulo R. Vasconcellos-Silva

RESUMO A linha de pesquisa em CienciArte, denominação que evoluiu numa trajetória de 30 anos de atividades unindo ciência e arte, vem sendo desenvolvida no Instituto Oswaldo Cruz/Fiocruz desde 2000. Ela testemunha a união de duas culturas, a fim de que ambas possam partilhar e contribuir com elementos essenciais ao ensino e à educação. Suas atividades assumem o pressuposto de que a associação da arte à educação científica possibilita ao ser humano desenvolver novas intuições e compreensões através da incorporação do processo artístico a outros processos investigativos, construindo um discurso sobre a relação entre arte, ciência, atividades humanas e tópicos relacionados a atividades multidisciplinares e multiculturais. Neste texto descrevemos a trajetória histórica da linha de pesquisa, a disciplina que dela derivou, incluindo relações entre conteúdos, referências e atividades diversas desenvolvidas. Essas abordagens atenderam aos mais diversos critérios de inclusão vinculados aos campos de atividade profissional de um ou mais componentes do grupo de estudos e práticas. Versaram sobre temas em ciência, saúde e arte evidenciando a aplicação do paradigma CienciArte e expressando a apropriação do conteúdo debatido ao longo dos anos. Uma figura síntese com a linha do tempo dessas ações mostra seus principais fatos. Entremeamos o texto com quatro "interlúdios" referentes a propostas que trabalhamos nos processos educacionais que conduzimos com CienciArte: (i) o manifesto CienciArte, (ii) as treze categorias cognitivas propostas pelo casal Root-Bernstein no livro Centelhas de gênios, (iii) a letra da música A ciência em si, de Gilberto Gil e Arnaldo Antunes, e (iv) a modelagem 5D com metaformação, de Tod Siler. Destacamos os referenciais teóricos que embasam a proposta, muito calcada na prática freireana de oficinas dialógicas. Temos convicção de que a linha de pesquisa atinge seus objetivos promovendo o diálogo entre a ciência e a arte, reforçando o conceito "ArtScience", ou, em português, "CienciArte".

PRELÚDIO: 0 CONTEXTO Este trabalho é realizado no Laboratório de Inovações em Terapias, Ensino e Bioprodutos (Liteb) do Instituto Oswaldo Cruz-Fundação Oswaldo Cruz (IOC-Fiocruz), Rio de 